\title{
A new modified technique of laparoscopic needle catheter jejunostomy: a 2-year follow-up study
}

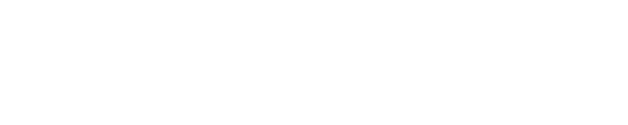

Peng Ye

Liping Zeng

Fenghao Sun

Zhou An

Zhoubin Li

Jian $\mathrm{Hu}$

Department of Thoracic Surgery, First Affiliated Hospital, College of Medicine, Zhejiang University, Hangzhou, People's Republic of China
Background: The aim of this study was to establish a modified technique for performing laparoscopic needle catheter jejunostomy.

Methods: From May 2011 to October 2013, laparoscopic needle catheter jejunostomy was performed in 21 patients with esophageal cancer. During the procedure, jejunal inflation was performed via a percutaneous 20-gauge intravenous catheter to facilitate the subsequent puncture of the jejunal wall by the catheter needle. The success rate, procedure time, complications, and short-term outcomes were evaluated.

Results: All laparoscopic needle catheter jejunostomies were technically successful, with no perioperative mortality or conversion to a laparotomy. The operation required a mean time of $51.4 \pm 14.2$ (range 27-80) minutes, and operative bleeding range was 5-20 mL. There was one reoperation required for one patient on postoperative day 5 , because the feeding tube was accidentally pulled out during sleep, by patient himself, and the second laparoscopic jejunostomy for this patient was performed successfully. One patient had puncture site pain and was successfully treated with oral analgesics. Other complications, such as gastrointestinal bleeding, intestinal perforation, intestinal obstruction, tube dysfunction, pericatheter leakage, and infection at the skin insertion site, were not observed. The 30-day mortality rate was $4.8 \%$ (one out of 21 ), which was not attributed to the procedure. Enteral nutrition was gradually administered 24-48 hours after operation.

Conclusion: The novel modified technique of laparoscopic needle catheter jejunostomy is a technically feasible, with a high technical success rate and low complication rate. Its specific advantage is simplicity and safety, and this modified approach can be considered for routine clinical use after long-term outcome evaluation.

Keywords: esophageal cancer, laparoscopy, needle catheter jejunostomy

\section{Introduction}

Patients with esophageal malignancy are usually unable to sustain weight on oral intake alone and present with malnutrition or even cachexy. Nutritional support is crucial for these patients.

Prolonged enteral tube feeding is invaluable in supplementing nutritional needs in patients with normal bowel function needing nutritional support. Along with the nasogastric tube, nasojejunal tube, and gastrostomy, jejunostomy is a typical approach for enteral nutrition support.

In the patients for whom enteral nutritional support is indicated, the percutaneous endoscopic route for gastric placement is currently the standard procedure for longterm support. The endoscopic placement of feeding tubes has limits in patients with severe stenosis of the upper gastrointestinal tract. However, the laparoscopic approach offers a viable alternative in these cases. Laparoscopic needle catheter jejunostomy has been reported to be safe and to have a low complication rate. ${ }^{1}$ The laparoscopic placement of a feeding tube is appropriate when a laparoscopic examination of the 
abdomen is planned in patients at risk for malnutrition or in cases where neoadjuvant therapy of upper gastrointestinal tumors, such as esophageal or pancreatic tumors, is indicated. Especially, patients requiring neoadjuvant therapy and a gastric pull-up for the treatment of esophageal cancer may benefit from this procedure.

Since the first report of direct intrajejunal feeding in 1858 by Busch, jejunostomy has been used for delivering enteral nutrition in a wide variety of clinical situations. ${ }^{1}$ With the development of this technique and great demand for minimization of the surgical invasion and cosmetic result, in the 1990s, O'Regan and Scarrow ${ }^{1}$ pioneered laparoscopic jejunostomy. Compared with traditional laparotomy, it is minimally invasive, has less complications, and is welltolerated. ${ }^{2,3}$ Following this primary report, numerous innovative strategies have evolved over the years. ${ }^{2,4-6}$

In this paper, based on the previous work, we presented a modified feasible and effective approach for three-port laparoscopic needle catheter jejunostomy.

\section{Materials and methods}

All patients had routine preoperative evaluation, with consents obtained for all, and the study was approved by the ethics committee of The First Affiliated Hospital, College of Medicine, Zhejiang University. All the cases were performed by the same surgeon.

The patients were placed in a supine position, and general anesthesia was induced. The abdomen was prepared and draped. A $10 \mathrm{~mm}$ transverse incision was made at the right lower quadrant, lateral to the lateral edge of abdominus rectus. A Veress needle was used for abdominal insufflation, followed by placement of a $10 \mathrm{~mm}$ trocar, through which the $30^{\circ}$ laparoscope (Karl Storz GmbH and Co. KG, Tuttlingen, Germany) was introduced. After the abdomen was explored for metastatic implants and hepatic metastases, another two ports were then placed for the working instruments under visualization: a $5 \mathrm{~mm}$ port in the midline midway between the umbilicus and the xiphoid process, and a $5 \mathrm{~mm}$ port in the left lower quadrant, lateral to the abdominus rectus muscle (Figure 1A).

The patient was placed in a slight reverse Trendelenburg position. The greater omentum and transverse colon were retracted cephalad, and the ligament of Treitz was identified. The proximal jejunum $20-30 \mathrm{~cm}$ away from the Treitz ligament, where the bowel could be elevated to touch the left upper-quadrant abdominal wall, was identified with laparoscopy, and the loop of jejunum was oriented.

A 20-gauge $(\mathrm{G}) \times 1.88$ inch intravenous (IV) catheter (BD Angiocath, ${ }^{\mathrm{TM}} 1.1 \times 48 \mathrm{~mm}$; BD Biosciences, Franklin Lakes, NJ, USA) (Figure 2) was introduced in the left upper quadrant below the costal margin (the proposed jejunal feeding tube exit site) (Figure 1), percutaneously into the peritoneal cavity, under direct vision. The first intracorporeal anchoring stitch (three in total, in a triangle configuration) was placed at the 10 o'clock position of the IV catheter puncture point. A Polysorb ${ }^{\text {TM }}$ 2-0 GL 123 absorbable suture was used to bite the anterior abdominal wall and then the seromuscular layer of the proximal jejunum (Figure 3A). After retraction of the IV catheter (still in the abdominal wall), the suture ends were tied, approximating the bowel to the anterior abdominal wall, avoiding jejunal injury during the approximation (Figure $3 \mathrm{~B}$ ). It is important to emphasize that the two tails of suture should not be cut and that a distal tail end, approximately $5 \mathrm{~cm}$, be left. Subsequently, the IV catheter was advanced only far enough to penetrate into the jejunal lumen (Figure 3C). Then the needle was withdrawn, leaving the catheter in the jejunal lumen, and the jejunum was insufflated through the catheter. Air inflation is recommended, because the fluid would flow away. The amount of the air for insufflation will vary, depending on the size of the jejunal loop and the degree of jejunal inflation (generally $50-100 \mathrm{~mL}$ is recommended).
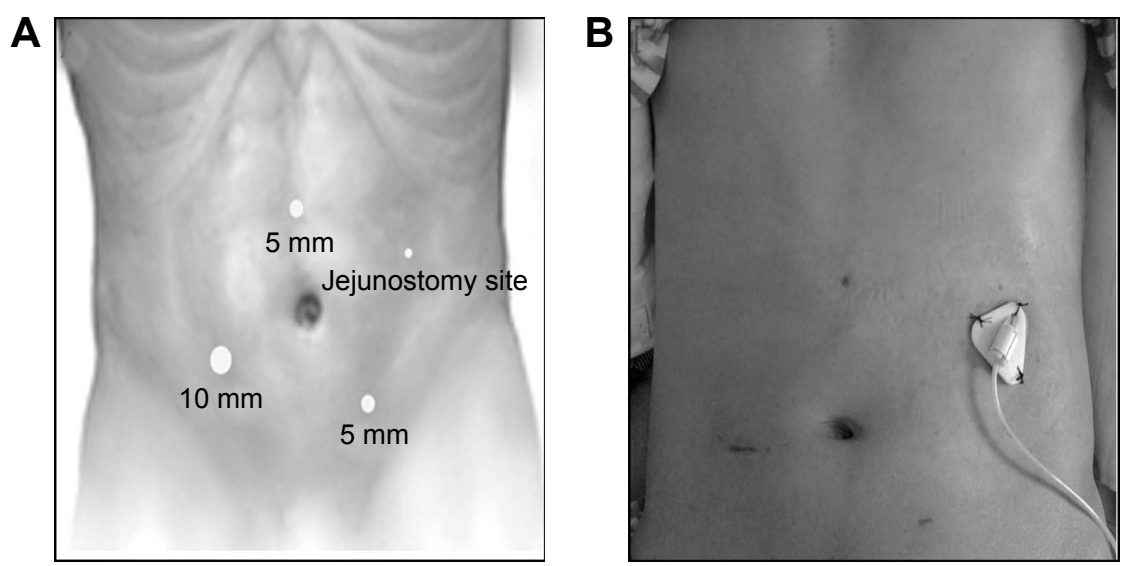

Figure I (A) Port positioning. (B) A 30-day postoperative view of incision of a 38-year-old male patient. 


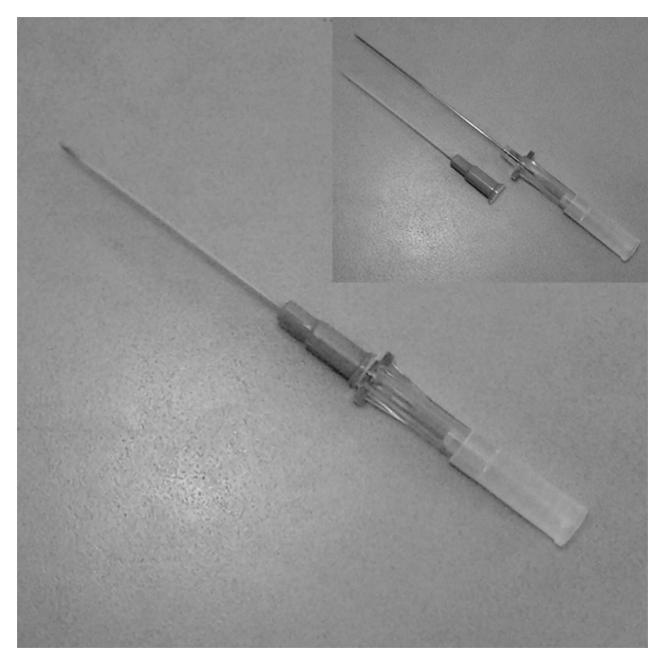

Figure 2 A 20-G IV catheter assembly. The smaller inset figure represents the 20-G needle and catheter, separated.

Abbreviations: G, gauge; IV, intravenous.
After the jejunal loop was inflated, catheter was removed. Then placement of the needle catheter jejunostomy was then performed with a needle catheter jejunostomy kit, (Freka ${ }^{\circledR}$-FKJ, CH/FR9; Fresenius Kabi GmbH, Bad Homburg, Germany). The introducer needle was passed percutaneously at the same position as the previous 20-G IV catheter, while visualizing the needle as it entered the abdomen and was inserted into the inflated jejunal lumen (Figure 3D). The feeding tube was then passed through the introducer needle, which was then removed. Intraluminal placement was confirmed by injecting saline into the tube, and the tube was advanced for $20-30 \mathrm{~cm}$ within the jejunal lumen when insufflating the jejunum. The introducer needle was removed, and the feeding tube was firmly secured in place with an intracorporeal purse-string suture, using the suture remaining at the first anchoring stitch (Figures $3 \mathrm{E}$ and F), and the tube was tested for leaks by flushing saline into
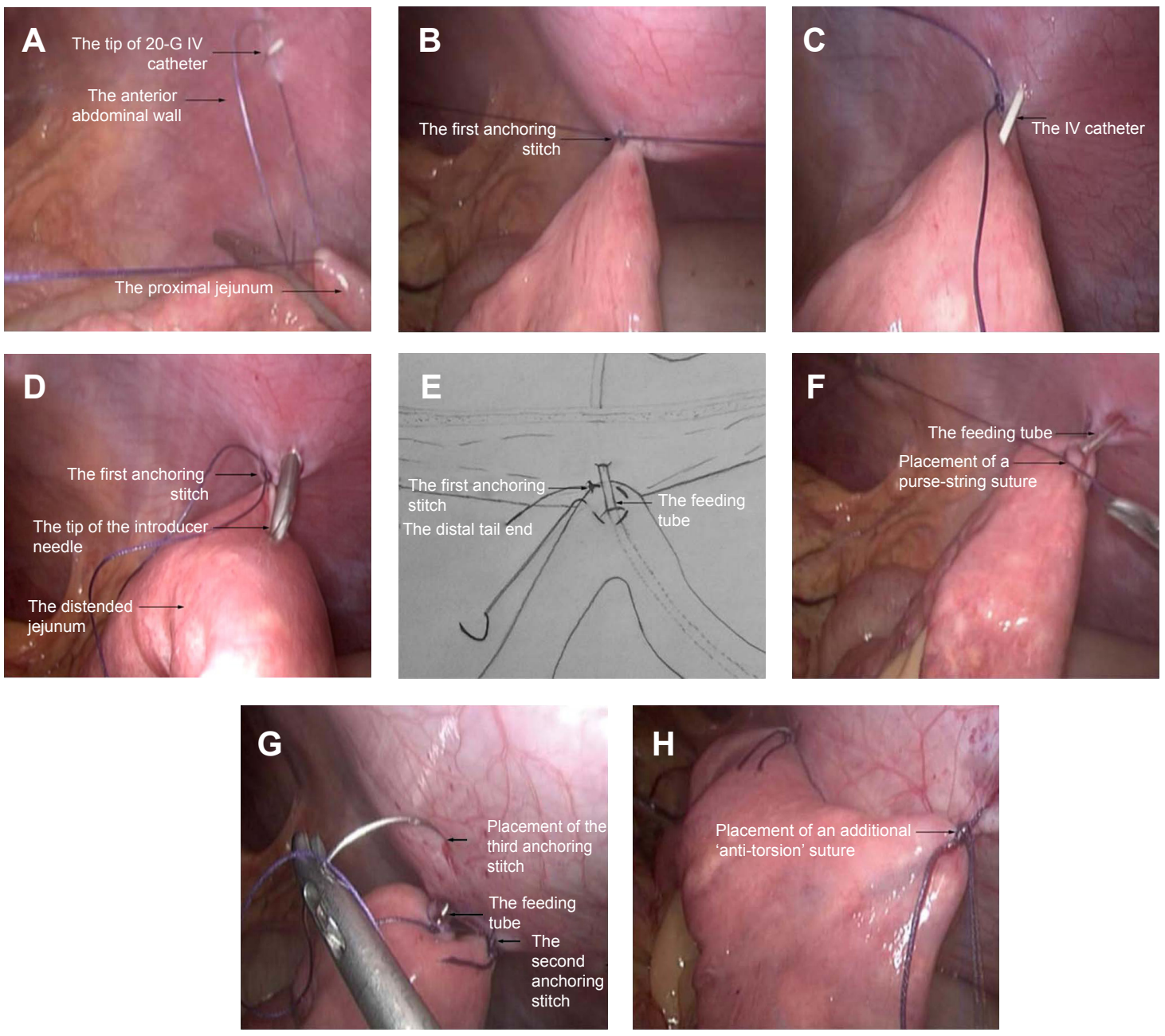

Figure 3 Demonstration of the modified laparoscopic needle catheter jejunostomy.

Notes: (A) The first anchoring stitch was placed at the 10 o'clock position of the IV catheter puncture point, taking a bite at the anterior abdominal wall and the seromuscular layer of the proximal jejunum. (B) Approximation of the bowel to the anterior abdominal wall (the IV catheter was retracted in the abdominal wall). (C) The IV catheter was advanced into the jejunal lumen. (D) Placement of the needle catheter jejunostomy into the distended jejunum. (E) A schematic view showing the purse-string suture around the feeding tube using intracorporeal suturing. (F) Intraoperative view of the placement of the purse-string suture. (G) Placement of the other two anchoring stitches around the feeding tube at the 2 and 6 o'clock position, respectively. $(\mathbf{H})$ The antitorsion suture was placed approximately $5 \mathrm{~cm}$ distally to fix the jejunum to the anterior abdominal wall. Abbreviation: IV, intravenous. 
the tube. Then, the jejunum was fixed to the anterior abdominal wall by another two anchoring stitches, at the 2 and 6 o'clock positions of the feeding tube, respectively (Figure 3G).

Subsequently, another suture was placed approximately $3 \mathrm{~cm}$ distally to assure a broad fixation to the anterior abdominal wall, to prevent potential volvulus at the jejunostomy site (Figure $3 \mathrm{H}$ ). Finally, the tube was secured externally to skin (Figure 1B), and the incision was closed with subcutaneous suture.

\section{Results}

We successfully performed 22 laparoscopic needle catheter jejunostomies in 21 patients (19 men and two women), with a mean age of 63.0 years (range 38-85), using this method over a 2-year period. Patient characteristics and preoperative clinical data are shown in Table 1. All patients were biopsied and diagnosed with esophageal carcinoma. Of the 21 newly diagnosed patients (81\%), 17 had esophageal obstruction from carcinoma and received chemotherapy or chemoradiation in 30 days after the procedure. The other four patients presented with malnutrition or cachexy as a side effect resulting from the undergoing chemotherapy or radiotherapy. The preoperative mean body mass index (BMI) was $18.7 \pm 2.3$ (range 16.1-23.0) kg/m², and nine out of 21 patients had a BMI level $<18.5 \mathrm{~kg} / \mathrm{m}^{2}$. Preoperative mean serum albumin was 35.4 \pm 5.4 (range 25.1-42.8) g/L, and eight out of 21 patients had a preoperative hypoalbuminemia $(<35 \mathrm{~g} / \mathrm{L})$.

All the laparoscopic needle catheter jejunostomies were technically successful, with no preoperative mortality or conversion to a laparotomy. The surgical details were shown in Table 2. The operation required a mean 51.4 \pm 14.2 minutes (range 27-80), with an operative bleeding of 5-20 mL. There was one reoperation for one patient on postoperative day 5 because the feeding tube was accidentally pulled out during sleep, by the patient himself; the second laparoscopic jejunostomy for this patient was performed successfully. One patient had puncture site pain and was successfully

Table I Patient characteristics and preoperative clinical data

\begin{tabular}{|c|c|}
\hline Number of patients & 21 \\
\hline Sex (male/female), $\mathrm{n}$ & $19 / 2$ \\
\hline Age, years, mean $\pm S D$ (range) & $63.0 \pm 12.7(38-85)$ \\
\hline $\mathrm{BMI}, \mathrm{kg} / \mathrm{m}^{2}$, mean $\pm \mathrm{SD}$ (range) & $18.7 \pm 2.3(16.1-23.0)$ \\
\hline Underweight (BMI < I8.5), n & $9 / 21$ \\
\hline Albumin, g/L, mean \pm SD (range) & $35.4 \pm 5.4(25.1-42.8)$ \\
\hline Hypoalbuminemia ( $<35 \mathrm{~g} / \mathrm{L})$, $\mathrm{n}$ & $8 / 21$ \\
\hline \multicolumn{2}{|l|}{ Indication } \\
\hline Esophageal carcinoma, $\mathrm{n}$ & $21 / 21$ \\
\hline Newly diagnosed, $n$ & $|7 / 2|$ \\
\hline Undergoing chemotherapy or radiotherapy, $n$ & $4 / 21$ \\
\hline
\end{tabular}

Abbreviation: BMI, body mass index. treated with oral analgesics. Other complications, such as gastrointestinal bleeding, intestinal perforation, intestinal obstruction, tube dysfunction, pericatheter leakage, and infection at the skin insertion site, were not observed. The 30 -day mortality rate was $4.8 \%$ (one out of 21 ). One patient with esophageal cancer died 3 weeks after the procedure, due to intestinal hemorrhage caused by severe myelosuppression induced by radiotherapy and chemotherapy, which was not attributed to the procedure. The enteral nutrition was gradually administered 24-48 hours after surgery (17 patients in 24 hours and four patients in 48 hours).

\section{Discussion}

Enteral feeding is the preferred option over parenteral nutrition in patients with normal bowel function who require prolonged nutrition support, ${ }^{7,8}$ and in some cases, a feeding jejunostomy is necessary. The techniques of constructing a feeding jejunostomy vary from open, laparoscopic, endoscopic, and radiologic techniques. Endoscopic, radiologic, and laparoscopic techniques have been proposed that avoid the potential risk of a laparotomy, if available.

Percutaneous endoscopic jejunostomy is a nonoperative technique of enteric feeding. ${ }^{9,10}$ However, it may be inaccessible for the endoscopic approach in patients with stenosis of the upper gastrointestinal tract because of tumor occlusion. It is also not a good choice for patients who will receive potential esophagectomy. In addition, the endoscopic approach was found to be less optimal for long-term needs, due to a higher incidence of tube dysfunction and aspiration. ${ }^{11,12}$

As to radiologic techniques, direct percutaneous jejunostomy under fluoroscopic guidance was introduced by Gray et $\mathrm{al}^{13}$ in 1987 , and since then many others have started to apply this technique and described their personal experience. ${ }^{14-17}$ This is a promising technique with several advantages, such as no need for general anesthesia, the ability to traverse tight esophageal strictures or gastric outlet obstructions,

Table 2 Surgical details

\begin{tabular}{ll}
\hline Surgical details & Results \\
\hline Laparoscopic needle catheter jejunostomies, $\mathrm{n}$ & 22 \\
Operation time, minutes, mean \pm SD (range) & $51.4 \pm \mathrm{I} 4.2$ (27-80) \\
Operative bleeding, mL, mean \pm SD (range) & $9.0 \pm 5.4(5-20)$ \\
Success rate, \% & 100 \\
Complications & \\
$\quad$ Tube dysfunction, $\mathrm{n}$ & 0 \\
Puncture site pain, $\mathrm{n}$ & $\mathrm{I}$ \\
Reoperation, $\mathrm{n}$ & $\mathrm{I}$ \\
30-day mortality, $\mathrm{n}$ & $\mathrm{I}$ \\
Wound infection, $\mathrm{n}$ & 0 \\
Others, $\mathrm{n}$ & 0 \\
\hline
\end{tabular}


and a lower likelihood of hemorrhage or long-term fistula on eventual withdrawal of the catheter because of the small catheter size.$^{18}$ However, the application of this complicated technique is relatively limited, perhaps due to the inherent technical difficulties, including targeting and puncturing of the mobile and compliant jejunum, and maintaining the position of the jejunum during catheter insertion. ${ }^{15}$

The total laparoscopic jejunostomy approach, which was mostly applied, is an ideal method for patients with esophageal malignancy. There are several advantages, such as staging of the malignancies during the procedure, provision of palliative nutritional support, and availability after possible esophagectomy. Among numerous techniques, needle catheter jejunostomy has been widely applied, with several advantages. First, it carries fewer complications than tube jejunostomy using the formerly popular Witzel technique. ${ }^{19}$ Second, it permits a good access for additional fluids and medications. Third, it could be performed by laparoscopic, endoscopic, and radiologic techniques. However, needle catheter jejunostomy placement is not free of complication and should be used appropriately. ${ }^{20,21}$

Our study introduced a new modified three-port total laparoscopic needle catheter jejunostomy. The typical advantages of laparoscopic surgery over traditional laparotomy are maintained in our method, such as less postoperative pain, reduced incidence of incisional hernia, improved cosmesis, and lower wound infection rates. What is more, it has the specific advantage of safety and simplicity.

Compared with other laparoscopic approaches, placement of the jejunal tube after jejunal inflation rather than directly was safer and more controlled. For percutaneous needle catheter jejunostomy, the puncture of the feeding tube is the key step for successful jejunostomy. The normal, undistended jejunum is difficult and at risk for puncture, especially when the procedure is performed laparoscopically. During fluoroscopic-guided percutaneous jejunostomy, several studies reported that injected air was used to distend the jejunum via an intrajejunal catheter (through the nose or mouth), to provide intraluminal support. ${ }^{14-17}$ Inspired by these valued experiences, it seems that distended jejunum would be easier and safer than normal collapsed jejunum for puncture. Thus, previous jejunal insufflation via a $20-\mathrm{G}$ needle before the puncture with feeding tube was proposed.

In the present study, our $100 \%$ technical success rate confirmed that our technique was feasible. It avoids the risk of accidental injury of the lateral or back wall of the jejunum during the puncture with the feeding tube. Further, the puncture by the angiocatheter and feeding tube are under direct visualization.
Secondly, the approach we proposed is relatively simple and less technically demanding than the earlier techniques. All three anchoring stitches around the feeding tube and the purse-string suture are placed intraperitoneally, and the only additional requirement in our approach is a common 20-G IV catheter, with no need of transabdominal sutures, ${ }^{2,22,23}$ T-fasteners, ${ }^{4,24,25}$ ENDO STITCH ${ }^{\text {TM }}$ automatic suturing device, etc, avoiding the risks and difficulties associated with them. In our study, a 20-G IV catheter was used to puncture the jejunum for insufflation with the expectation of enhancing safety. The type of needle may vary depending on the thickness of the abdominal wall and preference of surgeons. Generally, a common IV catheter (48 $\mathrm{mm}$ in length) is enough. For obese patients, a longer catheter with the same or smaller size is recommended. The present study has indicated that a $20-\mathrm{G}$ IV catheter can be used to puncture the jejunum safely. However, additional study is warranted to confirm its value. Due to the surgeon's preference, the Freka-FKJ needle catheter jejunostomy kit was used. However, any typical feeding tube can be used.

In addition, our major complication, reoperation, occurred in $4.8 \%$ (one out of 21 ), which was higher than the $1.8 \%$ rates noted in a previous report. ${ }^{3}$ This could be explained by the small series but might also possibly be prevented by better fixation, patient education, and nursing care in the future. One patient died because of the side effects of chemotherapy and radiotherapy, which were not related to placement or usage of the feeding jejunostomy. Our other complication rates are low, which is attributed to the safe and simple method we proposed, and possibly also the small series.

The present method of modified catheter jejunostomy is safe, effective, less invasive, has lower overall complication rates, and is simple compared with the traditional catheter jejunostomy. However, this study also had limitations, including small sample amounts, which provided insufficient data for comparison with the traditional catheter jejunostomy. Therefore, in a future study, we would investigate the application of this modified method with a large sample and perform a sufficient comparison.

\section{Conclusion}

In summary, laparoscopic needle catheter jejunostomy using a $20-\mathrm{G}$ vascular catheter for jejunal insufflation to facilitate the subsequent puncture by the jejunal feeding tube is feasible, safe, and simple, with a high technical success rate. It is a potential practical alternative to the other typical laparoscopic jejunostomy approaches. 


\section{Disclosure}

The authors report no conflicts of interest in this work.

\section{References}

1. O'Regan PJ, Scarrow GD. Laparoscopic jejunostomy. Endoscopy. 1990;22(1):39-40.

2. Miyatani H, Yoshida Y, Kiyozaki H. Cecal perforation with an ascending colon cancer caused by upper gastrointestinal endoscopy. Ther Clin Risk Manag. 2009;5(2):301-303.

3. Han-Geurts IJ, Lim A, Stijnen T, Bonjer HJ. Laparoscopic feeding jejunostomy: a systematic review. Surg Endosc. 2005;19(7):951-957.

4. Duh QY, Way LW. Laparoscopic jejunostomy using T-fasteners as retractors and anchors. Arch Surg. 1993;128(1):105-108.

5. Jenkinson AD, Lim J, Agrawal N, Menzies D. Laparoscopic feeding jejunostomy in esophagogastric cancer. Surg Endosc. 2007;21(2): 299-302.

6. Nguyen NT, Schauer PR, Wolfe BM, Ho HS, Luketich JD. Laparoscopic needle catheter jejunostomy. Br J Surg. 2000;87(4):482-483.

7. Kaminski MV Jr. Enteral hyperalimentation. Surg Gynecol Obstet. 1976;143(1):12-16.

8. Koruda MJ, Guenter P, Rombeau JL. Enteral nutrition in the critically ill. Crit Care Clin. 1987;3(1):133-153.

9. Ponsky JL, Aszodi A. Percutaneous endoscopic jejunostomy. Am J Gastroenterol. 1984;79(2):113-116.

10. Shike M, Latkany L, Gerdes H, Bloch AS. Direct percutaneous endoscopic jejunostomies for enteral feeding. Nutr Clin Pract. 1997; 12(1 Suppl):S38-S42.

11. Wolfsen HC, Kozarek RA, Ball TJ, Patterson DJ, Botoman VA. Tube dysfunction following percutaneous endoscopic gastrostomy and jejunostomy. Gastrointest Endosc. 1990;36(3):261-263.

12. DiSario JA, Foutch PG, Sanowski RA. Poor results with percutaneous endoscopic jejunostomy. Gastrointest Endosc. 1990;36(3):257-260.

13. Gray RR, Ho CS, Yee A, Montanera W, Jones DP. Direct percutaneous jejunostomy. AJR Am J Roentgenol. 1987;149(5):931-932.
14. Wheble GA, Benson RA, Khan OA. Is routine postoperative enteral feeding after oesophagectomy worthwhile? Interact Cardiovasc Thorac Surg. 2012;15(4):709-712.

15. van Overhagen H, Ludviksson MA, Laméris JS, et al. US and fluoroscopicguided percutaneous jejunostomy: experience in 49 patients. $J$ Vasc Interv Radiol. 2000;11(1):101-106.

16. Yang ZQ, Shin JH, Song HY, et al. Fluoroscopically guided percutaneous jejunostomy: outcomes in 25 consecutive patients. Clin Radiol. 2007;62(11):1061-1065; discussion 1066-1068.

17. Hu HT, Shin JH, Song HY, et al. Fluoroscopically guided percutaneous jejunostomy with use of a 21-gauge needle: a prospective study in 51 patients. J Vasc Interv Radiol. 2009;20(12):1583-1587.

18. Sparrow P, David E, Pugash R. Direct percutaneous jejunostomy - an underutilized interventional technique? Cardiovasc Intervent Radiol. 2008;31(2):336-341.

19. Adams MB, Seabrook GR, Quebbeman EA, Condon RE. Jejunostomy. A rarely indicated procedure. Arch Surg. 1986;121(2):236-238.

20. Sarr MG. Appropriate use, complications and advantages demonstrated in 500 consecutive needle catheter jejunostomies. Br J Surg. 1999; 86(4):557-561.

21. Myers JG, Page CP, Stewart RM, Schwesinger WH, Sirinek KR, Aust JB. Complications of needle catheter jejunostomy in 2,022 consecutive applications. Am J Surg. 1995;170(6):547-550; discussion 550-551.

22. Albrink MH, Foster J, Rosemurgy AS, Carey LC. Laparoscopic feeding jejunostomy: also a simple technique. Surg Endosc. 1992;6(5): 259-260.

23. Allen JW, Ali A, Wo J, Bumpous JM, Cacchione RN. Totally laparoscopic feeding jejunostomy. Surg Endosc. 2002;16(12):1802-1805.

24. Edelman DS, Unger SW. Laparoscopic gastrostomy and jejunostomy: review of 22 cases. Surg Laparosc Endosc. 1994;4(4):297-300.

25. Andreetti C, D'Andrilli A, Ibrahim M, et al. Effective treatment of post-pneumonectomy bronchopleural fistula by conical fully covered self-expandable stent. Interact Cardiovasc Thorac Surg. 2012; 14(4):420-423.
Therapeutics and Clinical Risk Management

\section{Publish your work in this journal}

Therapeutics and Clinical Risk Management is an international, peerreviewed journal of clinical therapeutics and risk management, focusing on concise rapid reporting of clinical studies in all therapeutic areas, outcomes, safety, and programs for the effective, safe, and sustained use of medicines. This journal is indexed on PubMed Central, CAS,

\section{Dovepress}

EMBase, Scopus and the Elsevier Bibliographic databases. The manuscript management system is completely online and includes a very quick and fair peer-review system, which is all easy to use. Visit http://www.dovepress.com/testimonials.php to read real quotes from published authors. 